\title{
II
}

\section{A CONTRIBUIÇÃO DA EDUCAÇÃO JURÍDICA POPULAR PARA A PROTEÇÃO DOS TERRITÓRIOS NA AMAZÔNIA PARAENSE: O CASO JURUTI VELHO!*}

\author{
Lincon Sousa Aguiar \\ Tania Suely Azevedo Brasileiro ${ }^{2}$
}

\section{Introdução}

$\mathrm{Na}$ sociedade globalizada, as pressões exercidas pelo capital sobre os territórios não mais se limitam à escala local, ou regional, mas também podem ser nacionais ou até mesmo globais. Grandes empresas multinacionais podem alterar substancialmente as dinâmicas socioeconômicas de territórios que atraem os interesses do mercado.

Desta maneira, para a compreensão dos conflitos territoriais na Amazônia é necessário entender o território em suas múltiplas dimensões, sejam elas físicas, materiais, jurídicas, políticas, geográficas, culturais, etc., bem como enquanto espaço de disputa, onde coexistem os mais variados interesses. A categoria poder é crucial para o debate. Os conceitos de dominação e apropriação também.

Os territórios da Amazônia têm sido alvo de muitos interesses estrangeiros para explorar seus recursos naturais, como floresta, rios, minérios, entre outros. Diversos megaprojetos de desenvolvimento (hidrelétricas, ferrovias, rodovias, mineração, garimpo) são pensados para a região sem realmente considerar o tamanho dos seus impactos socioambi-

\footnotetext{
*DOI - 10.29388/978-65-86678-45-1-0-f.41-70

${ }^{1}$ Mestrando em Educação na Amazônia pelo Programa de Pós-Graduação em Educação da Universidade Federal do Oeste do Pará. Bacharel em Direito (UFOPA, 2019). E-mail: linconaguiar97@gmail.com

${ }^{2}$ Professora Titular da Universidade Federal do Oeste do Pará (UFOPA), lotada do Instituto de Ciências da Educação (ICED), docente permanente dos Programas de pós-graduação em Educação na Amazônia (PPGE/EDUCANORTE) e do doutorado Sociedade, Natureza e Desenvolvimento (PPGSND/UFOPA). Líder do grupo de pesquisa PRAXIS UFOPA/CNPq. Orientadora do estudo. E-mail: brasileirotania@gmail.com
} 
entais e os interesses dos povos e comunidades que habitam tradicionalmente o espaço. Nota-se a contradição existente no ordenamento jurídico nacional quando percebemos que o mesmo Estado que tem a missão de proteger os territórios e as culturas é quem impulsiona esses projetos de grandes impactos.

Um exemplo de conflito territorial na Amazônia Paraense é o caso da exploração minerária de bauxita em Juruti Velho, no Município de Juruti/PA, uma cidade tipicamente amazônica, situada na região oeste do Pará, com ritmo próprio de interação com o tempo e com o espaço, formada por uma população eminentemente rural e uma economia baseada na extração de madeira e plantio de mandioca. A Região de Juruti Velho é a antiga sede do Município, cuja fundação remete ao ano 1818, quando foi batizada de Vila Amazônia. Contudo, a ocupação humana nesta parte da Amazônia se faz presente há séculos, considerando ser este um dos territórios dos povos conhecidos como Munduruku e Muirapinima.

A dinâmica das relações socioeconômicas desse município foi fortemente modificada após a descoberta de uma reserva de mais de 700 milhões toneladas de bauxita. A riqueza minerária inseriu Juruti no circuito internacional de comercialização da bauxita, a partir da instalação da Alcoa, em 2005. As transformações promovidas pela presença de uma multinacional trouxeram ou reforçaram problemas como: êxodo rural, inflacionamento populacional, exploração ilegal de madeira, assoreamento de igarapés, ocupações irregulares de terras, prostituição e abuso sexual contra menores (MARIALVA, 2011).

Nesse cenário, em parceria com as Irmãs Franciscanas de Maristella, uma congregação da Igreja Católica baseada na teologia da libertação, com relevante papel na articulação política local, o Núcleo de Assessoria Jurídica Universitária Popular (NAJUP) Cabano, organizou, entre março de 2018 e março de 2019, o Curso Formação de Lideranças Comunitárias O Direito Achado na Beira do Rio - experiência relatada em Aguiar (2020). Esta ação foi cadastrada na Ufopa como projeto de extensão e teve como objetivo auxiliar as comunidades de Juruti Velho - principal região impactada pelas atividades minerárias - na defesa de seu território, a partir da construção de espaços de discussão sobre temas relevantes do 
Direito e das Ciências Sociais, aplicados ao contexto amazônico e à linguagem popular (ALMEIDA, 2015; LUZ, 2008). Trata-se da promoção de uma Educação Popular compreendida enquanto instrumento político de conscientização e politização, voltado para a transformação das estruturas opressoras, por meio do trabalho libertador de construção de um novo saber (FREIRE, 2016; BRANDÃO, 1981).

A turma foi formada por pessoas com perfil de liderança, das mais experientes às mais jovens, pela indicação das Associações representativas das 18 comunidades que compõem a região de Juruti Velho. Os conteúdos do curso foram organizados em cinco módulos: I - Introdução ao estudo do Direito; II - Introdução ao Direito Constitucional; III - Direito à Terra e Direito ao Meio Ambiente; IV - Direito dos Povos e Comunidades Tradicionais; e V - Direito à Cidade e Bem Viver.

Desta forma, esta pesquisa busca responder à seguinte questão: de que maneira a Educação Jurídica Popular promovida no curso "O Direito Achado na Beira do Rio" contribuiu para a proteção dos direitos territoriais na região de Juruti Velho? Para respondê-la, inicialmente caracterizou-se as concepções de território e o conflito territorial existente em Juruti Velho. Em seguida, discutiu-se os fundamentos teórico-metodológicos da Educação Jurídica Popular. Por fim, analisou-se a formação de lideranças comunitárias de Juruti Velho no âmbito do curso "O Direito Achado na Beira do Rio".

\section{Conflitos territoriais na Amazônia paraense: resistência em face da mineração em Juruti Velho}

Existem múltiplas definições que buscam caracterizar o território. A Ciência Política oferece um entendimento mais objetivo sobre o conceito, voltado para uma concepção fortemente ligada ao ordenamento jurídico do país. Segundo Streck e Morais (2014, p. 170), o território seria o "Locus sobre o qual será fixado o elemento humano e terá lugar para o exercício do poder e aplicação do ordenamento jurídico-positivo estatal". Os autores complementam sua análise afirmando que: 
$\mathrm{Na}$ tradição, o território desempenha uma função positiva de que tudo e todos que se encontram nos seus limites ficam sujeito à sua autoridade e uma função negativa de exclusão de toda autoridade diversa daquela do Estado, sendo regido pelo princípio da efetividade, limitando-se ao espaço físico sobre o qual o Estado efetivamente exerce o seu poder soberano, podendo coexistir a soberania territorial de um Estado com a supremacia territorial de outro (ex. Canal do Panamá) (STRECK; MORAIS, 2014, p. 170).

O entendimento dos autores estudiosos da Ciência Política e da Teoria Geral do Estado ilustram bem como normalmente a questão territorial é discutida no âmbito do Direito. Enquanto parte central da concepção de Estado Moderno, o território, em síntese, seria o espaço físico necessário para o exercício da soberania de um país, onde as pessoas estariam submetidas à jurisdição de um único Estado. Percebe-se que a definição apresentada considera principalmente aspectos objetivos da realidade para a sua construção, como questões ligadas às normas estatais, e acaba deixando de lado questões subjetivas, como a relação de determinado grupo social com o espaço em que vivem, para além da relação com o Estado.

Por outro lado, a Geografia concebe o território de uma forma mais ampla, de maneira a considerar os seus aspectos objetivos e subjetivos. Haesbaert (2007) propõe uma discussão sobre território e territorialidade, superando os limites da concepção jurídico-política para envolver também as dimensões materiais e simbólicas existentes entre os sujeitos e seu lugar.

Desde a origem, o território nasce com uma dupla conotação, material e simbólica, pois etimologicamente aparece tão próximo de terra-territorium quanto de terreoterritor (terror, aterrorizar), ou seja, tem a ver com dominação (jurídico-política) da terra e com a inspiração do terror, do medo - especialmente para aqueles que, com esta dominação, ficam alijados da terra, ou no "temtorium" são impedidos de entrar. Ao mesmo tempo, por outro lado, podemos dizer que, para aqueles que têm o privilégio de plenamente usufrui-lo, o território pode inspirar a identificação (positiva) e a efeti- 
va "apropriação" (HAESBAERT, 2007, p. 20).

Em sua análise, o autor busca comprovar que o território “em qualquer acepção, tem a ver com poder, mas não apenas ao tradicional 'poder político'. Ele diz respeito tanto ao poder no sentido mais explícito, de dominação, quanto ao poder no sentido mais implícito ou simbólico, de apropriação" (HAESBAERT, 2007, p. 20-21). A aproximação do conceito de território à ideia de poder, amplamente concebido, assim como a diferenciação entre dominação e apropriação, são fundamentais para abordar a temática proposta neste artigo.

O domínio ou a apropriação do espaço perpassam pela existência de diferentes interesses que muitas vezes vão colidir entre si. Se faz necessária a compreensão dessas dimensões para se analisar as disputas territoriais que ocorrem na Amazônia, onde há uma relação simbólica muito antiga de povos e comunidades tradicionais com o espaço que ocupam fisicamente e se reproduzem culturalmente, e onde também se faz presente forças exógenas que objetivam a exploração dos recursos naturais.

Nesse sentido, em seu estudo sobre os usos do conceito geográfico "território" e sua relevância na análise de conflitos territoriais e socioambientais na Amazônia, Silva e Silva (2016) também concebem o poder como uma categoria central para a compreensão do território.

É possível definir o território, portanto, na perspectiva atual, como um recorte ou espectro do espaço geográfico definido por e a partir de relações de poder, controle, apropriação e uso, sendo que essas relações são definidas em termos políticos, institucionais, em termos econômicos e culturais. O conceito de território decorre da relação socioespacial e do ponto de vista metodológico, pode ser apreendido em perspectivas multiescalares e interescalares, seja em termos subjetivos, locais, regionais, nacionais e globais, desde que considere as lógicas de comando dos fluxos que o definem, entrecruzando normas globais com as normas locais (grifos nossos) (SILVA; SILVA, 2016, p. 52-53).

Um ponto importante acrescentado pelos autores à discussão que 
está sendo feita sobre o conceito de território é que as relações de poder ocorrem em perspectivas multiescalares e interescalares.

As disputas pela dominação ou apropriação de um território são entendidas como territorialização do espaço (HAESBAERT, 2007). A territorialização é justamente esse processo de tomar para si, ocupar o território de acordo com a lógica que almeja e com os símbolos que fazem parte de sua realidade. É um processo constante de exercício de poder sobre o lugar. $\mathrm{Na}$ Amazônia, grandes forças do mercado, aliadas com políticas estatais, têm atuado no sentido de desterritorializar os povos e comunidades habitam tradicionalmente a região.

Tendencialmente, o Estado capitalista na atualidade, em sua face neodesenvolvimentista, concentra suas ações no território a partir de investimentos em megaprojetos, políticas de investimentos em infraestrutura, planejamento e execução de obras com caráter concentrador, pois que, não atendem às reais necessidades das populações que são diretamente afetadas por elas. A dominação do território pelo interesse do Estado mascara a expropriação, a desterreação que é imposta aos povos, que tradicionalmente habitaram o espaço-lugar e fizeram de um determinado espaço o seu território. O valor de uso é substituído bruscamente pelo valor de troca, pois passa ao domínio do empreendedor que o submete para explorálo economicamente, em favor do grande capital (SILVA; SILVA, 2016, p. 53).

Silva e Silva (2016) retratam o processo de dominação exercido pelo Estado sobre os territórios na Amazônia alinhado aos interesses comerciais de grandes grupos econômicos e em desconformidade com os anseios dos seus moradores. Os autores destacam a substituição do valor de uso pelo valor de troca durante essa pressão exercida sobre os territórios, fenômeno também trabalhado por Haesbaert (2007) quando trata da desterritorialização imposta às comunidades tradicionais.

O conflito entre os moradores de Juruti Velho e a Alcoa exemplifica muito bem como ocorrem as pressões do capital internacional sobre os territórios na Amazônia. Os primeiros processos de embate com a multinacional em Juruti iniciaram-se no ano de 2000, em um contexto 
muito favorável para a implantação de grandes projetos na Amazônia. Rapidamente a empresa conseguiu o aval do governo do Estado para iniciar as pesquisas e os levantamentos junto às comunidades da região, chegando a obter, em 2005, a Licença Prévia e a Licença de Instalação. As autorizações concedidas durante esse período foram alvo de contestação do Ministério Público Federal e do Ministério Público do Estado do Pará, por supostamente conter várias irregularidades, notadamente a falta de legitimidade do Estado do Pará para a concessão das referidas licenças (SILVA, 2014; MONTEIRO, 2009).

O empreendimento em questão consiste na extração de bauxita, matéria prima do alumínio. O minério bruto de bauxita, terceiro elemento mais presente na natureza, é uma mistura de argila rica em óxido e hidróxidos de alumínio. O potencial de reserva encontrado em Juruti, conforme estudos geológicos disponibilizados pela empresa, são de aproximadamente quarenta e cinco anos, com previsão de produção anual estimada em seis milhões de toneladas e posteriormente de dez milhões de toneladas de bauxita. A Alcoa opera na linha de produção e gerenciamento de usinas de alumínio primário, alumínio industrializado e alumina. Nas últimas décadas, o início de processos de pesquisa na Amazônia ocorre paralelamente à consolidação da empresa no mercado mundial, em meio à intensificação do mercado e à ampliação de sua base tecnológica e de pesquisa (SILVA, 2014).

Com a ameaça da mineradora aos rios e às florestas, as comunidades intensificaram as reuniões e a comunicação entre as áreas que formam a região de Juruti Velho. Eram, majoritariamente, os religiosos que tentavam alertar sobre os perigos de um empreendimento minerador. Foram as Irmãs Franciscanas de Maristella que iniciaram a articulação das redes sociais ao questionarem o projeto e suas benesses. Foram elas as responsáveis por colocar a Alcoa em evidência no cenário internacional, ao divulgarem o manifesto "SOS Juruti Velho" na página da internet do Grupo de Trabalho Amazônico - a maior rede de Organizações Não Governamentais da Amazônia (WANDERLEY, 2008).

Um passo muito importante para a articulação política das comunidades de Juruti Velho se deu quando seus moradores descobriram o risco iminente de perder seu território, por conta de uma ação judicial a 
tramitar na Justiça Federal. A reação foi rápida e pontual: em uma assembleia com a presença de mais de 2.000 pessoas, ocorrida em 24 de março de 2004, é erguida, a partir da consciência da sua diversidade sociocultural e do autorreconhecimento enquanto comunidade tradicional (WANDERLEY, 2008; MONTEIRO, 2009), a Associação das Comunidades da Região de Juruti Velho (ACORJUVE) para concentrar os esforços de todas as comunidades da região em busca da regularização fundiária da área tradicionalmente ocupada por seus ancestrais na modalidade de Projeto de Assentamento Agroextrativista (PAE).

A fundação da ACORJUVE foi fundamental para a mobilização da região de Juruti Velho na luta pela sua regularização fundiária. Em 10 de novembro de 2005, o Instituto Nacional de Colonização e Reforma Agrária (INCRA) superou a morosidade que se arrastava há décadas, criando o PAE Juruti Velho por meio da Portaria SR 30, n. 18, com 109.551 hectares, atendendo a 1.998 unidades familiares (LOPES, 2012).

Apesar da criação do PAE Juruti Velho, os moradores não conseguiram barrar a continuidade do empreendimento, mas também não deixaram que ocorresse de qualquer forma. Em 2009 ocuparam a base de operações da Alcoa para exigir uma negociação franca com as lideranças da empresa. A ação resultou em uma reunião com o Presidente da empresa na América Latina e Caribe e em um acordo no qual a ACORJUVE receberia diretamente $1,5 \%$ da lavra e mais as Perdas e Danos, que seriam definidas posteriormente - até o momento não foram. A negociação consiste em uma gigantesca vitória fruto de uma articulação muito forte das comunidades de Juruti Velho. Contudo, uma década passada muitas lideranças contestam os benefícios da concessão.

A cidade, que chegou a se empolgar com a promessa de desenvolvimento trazida pelo empreendimento minerário, logo sentiu o peso social do neoextrativismo. As escolas, as estradas, os hospitais e os comércios não aguentaram a demanda de trabalhadores que vieram de várias partes da Amazônia e do Brasil em busca de empregos formais e não formais gerados a partir da instalação da Alcoa. As transformações pro- 
movidas pela presença de uma multinacional no Município trouxeram, ou reforçaram, problemas como: inflacionamento populacional, êxodo rural, exploração ilegal de madeira, assoreamento de igarapés, ocupações irregulares de terras, prostituição e abuso sexual contra menores (MARIALVA, 2011). Portela (2017, p. 120) corrobora e anuncia, denunciando:

Pode-se afirmar que a situação de conflito permanece em Juruti como um clima que paira no ar. As insatisfações e conflitos envolvendo as comunidades diretamente atingidas pelo empreendimento minerador, as ocupações de terras reivindicadas pela ALCOA e as reintegrações de posse obtidas judicialmente pela empresa, que impôs sérios prejuízos aos ocupantes invasores com a derrubada de seus barracos, como ocorreu em 2017 denunciam a tensão do conflito existente em Juruti. A paz é apenas aparente, as disputas pelo controle e uso dos recursos naturais (peixes, caças, frutas, madeiras etc.), e os conflitos pela posse da terra continuam e se intensificaram após a chegada da ALCOA no município de Juruti.

Segundo Portela (2017), o povo de Juruti Velho não desiste de lutar por dignidade, pela efetivação de seus direitos, pela proteção das pessoas, florestas, dos rios e lagos de seu território. Apoiados pelas Irmãs Franciscanas de Maristella, as lideranças comunitárias buscam participar de cursos e formações para auxiliarem nas lutas travadas nas suas comunidades ou até mesmo para trabalharem na resolução de conflitos internos.

Assim, o diálogo entre o NAJUP Cabano da Universidade Federal do Oeste do Pará (UFOPA) e as lideranças comunitárias de Juruti Velho, promovido por meio do curso O Direito Achado na Beira do Rio, emerge nesse cenário como uma prática de fortalecimento da articulação comunitária. A discussão sobre temas introdutórios do Direito a partir da realidade concreta dos jurutienses vem para auxiliar aos comunitários locais a entenderem-se enquanto sujeito de direitos e a entender quais são os caminhos para a efetivação destes. 


\section{Fundamentos da educação jurídica popular: remando para a construção de um diálogo crítico e libertador no campo do direito}

No Brasil, o sistema educacional está longe de entregar à maior parte da população uma Educação pública, gratuita e de qualidade. O projeto de Educação que tem sido levado adiante pelo Estado, mesmo durante os governos mais progressistas, não se preocupou em construir uma nação autônoma em relação aos outros países e nem se preocupou com a humanização dos educandos. Pelo contrário, mostrou-se essencialmente voltado para atender aos interesses neoliberais do mercado globalizado, aceitando uma posição submissa ordem internacional, em vez de construir um projeto nacional popular (FRIGOTTO, 2006). Dessa forma, a Educação deixa de atender aos interesses emancipatórios e passa a ser compreendida enquanto mercadoria em potencial, com a justificativa da "dupla constatação da superioridade do capitalismo, enquanto organizador das relações sociais, e dos princípios da economia neoliberal para potencializar as pontencialidades do capitalismo através da privatização, desregulação, mercadorização e globalização" (SANTOS, 2011, p. 32).

Esse "empacotamento" do conhecimento é uma das formas do capitalismo se reproduzir na sociedade. Por meio do enfraquecimento da Educação pública ou até mesmo de sua própria construção enquanto estrutura naturalmente deficiente, as ideias reacionárias ganham terreno e são difundidas como se fossem dadas no mundo. Severino (2004, p. 305) afirma que "toda essa pedagogia em vez de levar os sujeitos a entender o mundo, mistifica o mundo, manipulando-o para produzir a ilusão da felicidade. Prosperidade essa, prometida, mas nunca realizada".

Mészáros (2008) destaca o papel da Educação institucionalizada na reprodução da lógica capitalista, especialmente na "internalização" nos indivíduos de qual deve ser sua posição nos estratos sociais:

A educação institucionalizada, especialmente nos últimos 150 anos, serviu - no seu todo - ao propósito de não só fornecer os conhecimentos e o pessoal necessário à máquina produtiva em ex- 
pansão do sistema do capital, como também gerar e transmitir um quadro de valores que legitima os interesses dominantes, como se não pudesse haver nenhuma alternativa à gestão da sociedade, seja na forma "internalizada" (isto é, pelos indivíduos devidamente “educados" e aceitos) ou através de uma dominação estrutural e uma subordinação hierárquica e implacavelmente impostas (MÉSZAROS, 2008, p. 35).

Essa modalidade de Educação, que objetifica os seres humanos e lhes retira toda a liberdade e a autonomia para ser no mundo, é denominada por Paulo Freire de Educação bancária. A Educação bancária concebe os estudantes como seres desprovidos de conteúdo, páginas em branco, recipientes, vasos a serem preenchidos pelas informações oferecidas pelos professores, aqueles que dominam o conhecimento. "A narração, de que o educador é o sujeito, conduz os educandos à memorização mecânica do conteúdo narrado" (FREIRE, 2016, p. 104). "O educador se põe frente aos educandos como sua antinomia necessária. Reconhece na absolutização da ignorância daqueles a razão de sua existência" (FREIRE, 2016, p. 105).

Dessa forma, percebemos que a Educação institucional não somente tem falhado em atender aos seus potenciais emancipatórios como tem servido como estrutura para a fomentação das desigualdades. Enquanto parte crucial para a sustentação do sistema capitalista, mesmo com diversas reformas, a Educação pública é eficiente em debilitar a formação profissional, acadêmica e humanística das classes populares.

Uma das principais consequências da desfuncionalidade programada do sistema público de Educação é a falta de conhecimento dos próprios direitos. A compreensão dos direitos e deveres é essencial para o exercício da cidadania e para a existência de uma sociedade democrática. A Constituição da República Federativa do Brasil promulgada em 1988 (BRASIL, 1988), após a reivindicação histórica dos movimentos sociais, consagrou uma série de direitos sociais e direitos fundamentais, que a tornou um dos textos mais avançados do mundo em matéria constitucional. 
Contudo, a desinformação da população em relação a seus direitos faz com que haja uma dificuldade para a efetivação do texto legal. $O$ afastamento das classes populares do universo jurídico é algo que sempre esteve presente em nosso país. A linguagem do Direito foi pensada pelas elites para a manutenção de seus privilégios e por isso foi propositalmente construída de forma a dificultar a participação das camadas populares. O povo não entende muito bem como funciona o Sistema de Justiça porque ele não foi feito para ser apropriado pelo povo, mas, pelo contrário, foi criado para controlar seus impulsos contra a ordem estabelecida.

Nesse sentido, a Educação Jurídica Popular "preocupa-se com a falta de conhecimento desses segmentos sociais excluídos pelo fato de não se reconhecerem como sujeitos de direitos, fator que vai interferir na falta de participação popular no cotidiano da vida social e no exercício da cidadania" (OLIVEIRA, 2015, p. 17). Ela surge como uma concepção voltada para a ampliação dos debates sobre os direitos e garantias fundamentais junto às classes populares com o objetivo de auxiliá-las em seus processos de luta pela efetivação de direitos e construção de novas categorias jurídicas. No diálogo sincero e amoroso com as lideranças populares, pretende-se, ao mesmo tempo que se socializa os conhecimentos da academia e dos tribunais, oportunizar espaços para a construção de novos saberes necessários para a transformação social.

O movimento de educação jurídica popular insere-se, desse modo, dentro de um amplo projeto político-social como estratégia profícua a efetivar a concretização dos direitos fundamentais ao setor populacional que deles mais necessita: as minorias e os oprimidos sociais. A partir das bases ideológicas pedagógicas e jurídicas libertárias e emancipatórias, os projetos de educação jurídica social visam capacitar as lideranças comunitárias de setores socialmente vulneráveis e a própria população em geral sob o intuito de estimular nestes a quebra da sua posição de passividade (RONTONDANO, 2015, p. 100).

No âmbito das Ciências Jurídicas, a Educação Jurídica Popular está associada à da Assessoria Jurídica Popular, uma prática insurgente que se diferencia da assistência jurídica tradicional e pretende acompa- 
nhar dialogicamente grupos e movimentos populares na reivindicação por seus direitos, de forma a se apresentar como um parceiro político (LUZ, 2008). A principal fundamentação teórica está no Pluralismo Jurídico (WOLKMER, 2002) e mais especificamente na concepção de $\mathrm{O}$ Direito Achado na Beiro do Rio que é abordada na seção anterior (SOUSA JUNIOR, 2011). Assim, a Educação Jurídica Popular foge das correntes tradicionais do Direito e abraça as proposições críticas existentes, ao mesmo tempo em que se coloca como caminho para a construção de novas teorias e epistemologias jurídicas.

Por outro lado, a Educação Popular é a metodologia pela qual a Educação Jurídica Popular orienta a sua prática. O caráter diferenciador da Educação Popular para as outras concepções de Educação é que ela está voltada para fornecer mecanismos para a construção de uma sociedade protagonizada pela classe trabalhadora. Segundo Freire (2018, p. 208) "o grande objetivo da Educação Popular está em atender os interesses das classes populares que há quinhentos anos estão sendo negados". O filósofo brasileiro continua seu raciocínio afirmando que, "de um modo mais radical, a Educação Popular significa, para mim, caminhos, isto é, o caminho no campo do conhecimento e o caminho no campo político, através dos quais amanhã - e aí vem a utopia - as classes populares encontrem o poder" (FREIRE, 2018, p. 208).

As características principais da Educação Popular são enumeradas por Carlos Rodrigues Brandão em sua obra denominada O que é Educaşão Popular - um dos mais importantes escritos sobre o assunto em nosso país:

A partir de uma crítica feita ao sistema vigente de educação (ver isto em Educaşão como Prática da Liberdade, de Paulo Freire) e, especialmente, das formas tradicionais de educação de adultos e de trabalhos agenciados de desenvolvimento de comunidades e suas variantes, a educação popular: 1) constitui passo a passo ("aos tropeços", dirão os seus críticos) uma nova teoria, não apenas de educação, mas das relações que, considerando-a a partir da cultura, estabelecem novas articulações entre a sua prática e um trabalho po-

\footnotetext{
${ }^{3}$ Essa relação profunda com o poder interessa bastante à colocação no debate sobre os conflitos territoriais, onde percebendo o conflito de interesses, a Educação Popular em sua essência se coloca ao lado dos oprimidos, isto é, dos moradores tradicionais.
} 
lítico progressivamente popular das trocas entre o homem e a sociedade, e de condições de transformação das estruturas opressoras desta pelo trabalho libertador daquele; 2) pretende fundar não apenas um novo método de trabalho "com o povo" através da educação, mas toda uma nova educação libertadora, através do trabalho do/com o povo sobre ela - este é o sentido em que a educação popular projeta transformar todo o sistema de educação, em todos os seus níveis, como uma educação popular; 3) define a educação como instrumento político de conscientização e politização, através da construção de um novo saber, ao invés de ser apenas um meio de transferência seletiva, a sujeitos e grupos populares, de um "saber dominante" de efeito "ajustador" à ordem vigente — este é o sentido em que ela se propõe como uma ampla ação cultural para a liberdade a partir da prática pedagógica no momento de encontro entre educadores-educandos e educandos-educadores; 4) afasta-se de ser tão somente uma atividade "de sala de aula", de "escolarização popular", e busca alternativas de realizar-se em todas as situações de práticas críticas e criativas entre agentes educadores "comprometidos" e sujeitos populares "organizados", ou em processo de organização de classe; 5) procura perder, aos poucos (o que nem sempre consegue), uma característica original de ser um movimento de educadores e militantes eruditos destinado a "trabalhar com o povo", para ser um trabalho político sem projeto próprio e diretor de ações pedagógicas sobre o povo, mas a serviço dos seus projetos de classe. Este é o sentido em que há, hoje em dia um consenso de que a missão do educador popular é participar do trabalho de produção e reprodução de um saber popular, aportando a ele, ao longo do trabalho social e/ou político de classe, a sua contribuição específica de educador: o seu saber erudito (o da ciência em que se profissionalizou, por exemplo) em função das necessidades e em adequação com as possibilidades de incorporação dele às práticas e à construção de um saber popular (BRANDÃO, 1981, p. 46-47).

A partir do delineamento desses traços fundamentais, percebemos que a Educação Popular é um projeto de transformação social em que os educadores, inicialmente os professores da Universidade e profis- 
sionais de várias áreas, trabalham junto com os movimentos populares e grupos sociais marginalizados para que esses possam enxergar com precisão as forças opressoras que pesam sobre si e pensar autonomamente em horizontes alternativos. Isto é, tem-se a dimensão de que os educandos não são sujeitos passivos de um projeto de libertação pensado pelos intelectuais, mas que são eles próprios os protagonistas legítimos para a construção das estratégias de luta.

O papel do intelectual militante não é outro senão o de facilitar a compreensão das lideranças populares sobre assuntos de que foram outrora afastadas das discussões por razões históricas, no âmbito da sociedade colonial, racista, patriarcal e capitalista. Isso significa entender o ato de conhecer como uma "tarefa de sujeitos, não de objetos" e que "é como sujeito, e somente enquanto sujeito, que o homem pode realmente conhecer" (FREIRE, 2013, p. 28). O Educador Popular não deve subestimar a capacidade intelectual das massas, mas deve colocar os seus serviços acadêmicos e profissionais a serviço da problematização da realidade dos oprimidos. Assim,

A educação que se impõe aos que verdadeiramente se comprometem com a libertação não pode fundar-se numa compreensão dos homens como seres vazios a quem o mundo "encha" de conteúdos; não pode basear-se numa consciência especializada, mecanicistamente compartimentada, mas nos homens como "corpos conscientes" e na consciência como consciência intecionada ao mundo. Não pode ser a do depósito de conteúdos, mas a da problematização dos homens em suas relações com o mundo (FREIRE, 2016, p. 118).

Dessa forma, no fazer Educação Jurídica Popular, os educadores não vão ao encontro das lideranças comunitárias para transmitir os conhecimentos científicos, mas para problematizar a realidade dos oprimidos a partir das discussões que privilegiadamente têm acesso, ou seja, "a tarefa do educador, então, é a de problematizar aos educandos o conteúdo que os mediatiza, e não a de dissertar sobre ele, de dá-lo, de estendêlo, de entregá-lo, como se tratasse de algo já feito, elaborado, acabado, terminado" (FREIRE, 2013, p. 112). Não podem ir com a intenção de li- 
bertar ninguém, porque "Ninguém liberta ninguém, ninguém se liberta sozinho. Os homens se libertam em comunhão" (FREIRE, 2016, p. 120).

É nesse contexto que se encaixa a Educação Jurídica Popular: uma prática educativa e jurídica contra-hegemônica em que advogados populares, professores e estudantes do Curso de Direito vão ao encontro das classes populares para dialogar sobre a realidade opressora em que estão sugeridos, facilitando a compreensão de seus direitos em uma situação concreta e fornecendo ferramentas para que possam pensar autonomamente no enfrentamento de suas dificuldades.

A aplicação da Educação Jurídica Popular torna-se uma proposta de trabalho teórico-prático na aproximação do saber jurídico da universidade e a sociedade que há tempos ficaram tão distanciados. Através dessa atuação, o saber jurídico historicamente elitizado ganha uma roupagem popular a favor da condição de Cidadania iniciada pelo simples conhecer dos deveres, direitos e o acesso à justiça (BEZERRA; BICHARA, 2010, p. 89).

Segundo Souza (2019, p. 191) “a Educação Jurídica Popular teria esse papel de forjar a consciência das lideranças de base, para que estes, junto às suas comunidades no interior dos espaços sociais fomentem a transformação social". Conforme Freire (2016, p. 71), os oprimidos "somente superam a contradição em que se acham quando o reconheceremse oprimidos os engaja na luta por libertar-se" e esta "superação exige a inserção crítica dos oprimidos na realidade opressora, com que, objetivando-a, simultaneamente atuam sobre ela" (FREIRE, 2016, p. 75). Dessa maneira, cabe aos Educadores Jurídicos Populares o papel de criar condições práticas para as lideranças populares apropriarem-se do funcionamento básico do ordenamento jurídico e dominarem algumas das técnicas que possam ser relevantes em sua realidade concreta, como a produção de denúncias de queimadas e desmatamento ou a expedição de ofícios.

Nesse sentido, um grande cuidado que se deve ter é o de não se empolgar com as técnicas metodológicas da Educação Popular 
(ALMEIDA, 2015) e esquecer-se da técnica jurídica, porque muitas vezes as lideranças já possuem uma compreensão crítica da realidade, mas lhe faltam ferramentas para seu enfrentamento. Os diálogos não podem se limitar apenas à promoção de uma crítica bem fundamentada - devem caminhar no sentido de soluções para os problemas concretos.

Portanto, a Educação Jurídica Popular vai ao encontro do povo para, com ele, pronunciar o mundo, dar voz àqueles e àquelas que são silenciados pela sociedade, afirmar-se coletivamente enquanto sujeito de direitos. A questão está no reconhecimento das diversas formas de opressão da sociedade capitalista, colonial, racista, machista etc. para orientar a luta pela libertação.

\section{Diálogos entre os saberes acadêmicos e os saberes popu- lares na vila Muirapinima: o curso de formação de lide- ranças comunitárias o direito achado na beira do rio}

A origem do Curso de Formação de Lideranças Comunitárias O Direito Achado na Beira do Rio se dá a partir da aprovação de um projeto de extensão na Ufopa. Estudantes do curso de Direito foram convidados pelas Irmãs Franciscanas de Maristella e pela Comissão Pastoral da Terra da Diocese de Óbidos/PA para facilitar um dos módulos do Curso Técnico em Direito em julho de 2017. Após as primeiras aproximações, os estudantes reuniram-se com outros colegas da universidade que pensavam criticamente o fenômeno jurídico e decidiram por reestruturar um projeto iniciado em 2010: o NAJUP Cabano.

O NAJUP Cabano é um coletivo composto principalmente por estudantes do curso de Direito da Ufopa, voltado para o assessoramento jurídico das lutas de movimentos sociais, grupos sociais marginalizados, povos e comunidades tradicionais na região do Tapajós. Trata-se de um projeto articulado nacionalmente com outros grupos de Assessoria Jurídica Universitária Popular que buscam utilizar as ferramentas privilegiadamente acessadas na academia para potencializar as lutas por efetivação por direitos humanos, de forma alinhada aos interesses da classe trabalhadora. Segundo Corrêa (2018, p. 127), 
A assessoria jurídica popular se constitui como uma prática jurídica diferenciada dedicada à realização de ações para a garantia do acesso ao direito e à justiça a grupos subalternizados e movimentos ou grupos organizados em torno da luta por direitos, mesclando atividades de assistência jurídica e de educação popular em direitos humanos, organização comunitária e participação popular.

Em seus primeiros anos de existência, as principais ações do NAJUP Cabano estavam direcionadas para a atuação junto ao movimento estudantil e para a fomentação de debates sobre o pensamento jurídico crítico - quase inexistes à época. Destaca-se a organização de nove edições do Festival de Direitos e dos encontros preparatórios para o Festival, conhecidos como Diálogos Insurgentes, onde eram debatidos textos com o enfoque crítico no Direito.

Entre 2015 e 2017 o núcleo passou por um período de renovação, com a entrada de novos membros e o afastamento daqueles mais antigos. A chegada de novos professores na universidade foi um ponto crucial para a rearticulação do grupo. Em 2017, após debates sobre as limitações e possibilidades da institucionalização do NAJUP, foram aprovados um projeto e quatro planos de trabalho de extensão, sendo um deles para trabalhar em Juruti Velho. Esta foi a primeira linha de atuação a atuar diretamente com uma comunidade ou um movimento popular e é atualmente a mais antiga e consolidada.

O apoio da Ufopa para o projeto tem papel bastante relevante para a sua execução. Dentre as principais contribuições da instituição, destacam-se: o oferecimento de uma bolsa de graduação para o acompanhamento de um plano de trabalho; a disponibilização de um espaço físico para a realização de reuniões; o apoio administrativo para a emissão de certificados e para conseguir os materiais de escritórios necessários. Contudo, a Universidade não conseguiu alcançar algumas dimensões do diálogo proposto pelo NAJUP, como auxílio para o deslocamento para outro município.

A escolha do nome do curso é um resgate da identidade do NAJUP Cabano desde os primeiros Festivais de Direitos organizados. "O Direito Achado na Beira do Rio" é uma adaptação de "O Direito 
Achado na Rua", concepção de direito de grande reconhecimento dentro da seara jurídica crítica pensada inicialmente por Roberto Lyra Filho e consolidada por José Geraldo de Sousa Júnior. Esta é uma visão plural das relações jurídicas, que reconhece nas práticas dos sujeitos organizados coletivamente a possibilidade de "determinar o espaço político no qual se desenvolvem as práticas sociais que enunciam direitos ainda que contra legem" (SOUSA JUNIOR, 2011, p. 91). Além disso O Direito Achado na Rua é também o nome de uma coleção de livros pensada para a formação das AJUPs e também dos movimentos sociais (SOUSA JUNIOR, 1993).

Desta maneira, em uma releitura amazônica da expressão O Direito Achado na Rua, O Direito Achado na Beira do Rio compreende a centralidade dos Rios para se pensar as relações sociais, nas cidades da região amazônica. Montoia e Costa (2019), baseados em Cruz (2004), ao discutirem a formação da identidade do ribeirinho nas cidades amazônicas, concebem o rio em três importantes dimensões: espaço físico-natural, como o meio de transporte, a fonte de recursos e ainda como "responsável" pelo ritmo; espaço simbólico, mediador das "tramas sociais"; e espaço simbólico, enquanto "matriz do pensamento imaginário, do sistema de crendices, histórias, lendas, mitos, da cosmologia que insiste em permanecer como fator de resistência" (MONTOIA; COSTA, 2019, p. 189). Em complemento à análise, Cruz (2004) afirma que mesmo com as transformações causadas pela modernidade nas cidades ribeirinhas da Amazônia, "temporalidade e a espacialidade continuam marcadamente simbolizadas pelo rio, com uma vida dinamizada pelas interações materiais, simbólicas e imaginárias diferenciadas com ele" (CRUZ, 2004, p. 51).

"Remando" na direção da construção teórica deste conceito em movimento, este trabalho analisa o Direito em sua manifestação popular na Amazônia permeada pelos seus rios, mais especificamente o Direito Achado na Beira do Lago Muirapinima em Juruti Velho, Juruti/PA. O Direito Achado na Beira do Rio destaca a Beira do Rio como cenário de intensa manifestação do Direito nas cidades ribeirinhas da Amazônia, seja em processos de reivindicação ou de construção de novas categorias.

Ademais, o Curso O Direito Achado na Beira do Rio contou com cinco módulos: Introdução ao Direito; Direito Constitucional; Di- 
reito ao Território e ao Meio Ambiente; Direito dos Povos e Comunidades Tradicionais e Direito à Cidade e Bem Viver. Os encontros ocorreram no Centro de Formação Irmã Brunhilde localizado na Vila Muirapinima e tinham a duração de três dias (sexta-feira, sábado e domingo). $\mathrm{O}$ primeiro módulo ocorreu em abril de 2018 e o último em abril de 2019. Cerca de 30 lideranças indicadas pelas 18 associações comunitárias de Juruti Velho participaram dos diálogos. Formou-se uma turma bastante diversa, com a presença de pescadores artesanais, estudantes, professores, trabalhadores rurais, membros de associações, membros das paróquias, donas de casa, etc. A logística do curso foi planejada pelas Irmãs Franciscanas de Maristella, que viabilizaram transporte, alimentação e hospedagem para três facilitadores do NAJUP Cabano acompanharem cada módulo.

Há que se pontuar que a experiência analisada neste artigo, isto é, o Curso de Formação de Lideranças Comunitárias O Direito Achado na Beira do Rio, foi construída em um contexto de grande necessidade de promoção de debates, mas também de inexperiência metodológica. $\mathrm{O}$ projeto foi protagonizado por estudantes do Curso de Direito da Ufopa que estavam iniciando a sua formação em Assessoria Jurídica Popular e Educação Popular, tendo como primeira atividade prática o Curso O Direito Achado na Beira do Rio. Então, houve alguns deslizes naturais para quem está dando os primeiros passos.

Não obstante, os diálogos ocorridos na Vila Muirapinima possuem diversas potencialidades emancipatórias. As trocas de conhecimentos entre a Universidade e a Comunidade instigaram ambos a pensar criticamente outras dimensões de sua própria realidade e buscar novas alternativas para o fortalecimento das lutas por direitos. Trata-se do primeiro Curso de Formação de Lideranças Comunitárias de longa duração organizado pelo NAJUP Cabano em toda a região Oeste do Pará. A partir dessa experiência foram construídos outros espaços semelhantes, como o Curso O Direito Achado no Dia a Dia, para moradores da Ocupação Vista Alegre do Juá, o Curso Direitos Humanos e Consulta Prévia, para lideranças de povos e comunidades tradicionais de Santarém/PA e também o Ciclo de Oficinas de Direito À Cidade nas Escolas, para estudantes de ensino médio da rede pública de Santarém/PA. 
Neste trabalho, buscou-se analisar as contribuições desse curso de extensão para a proteção do Território de Juruti Velho, que desde 2005 encontra-se registrado no ordenamento jurídico como Projeto de Assentamento Agroextrativista (PAE) Juruti Velho. Inicialmente ressaltase que, devido à distância entre a Vila Muirapinima em Juruti/PA e a cidade de Santarém $/ \mathrm{PA}^{4}$, o primeiro contato com os participantes do curso se deu somente no primeiro módulo - antes disso conversou-se apenas com as Irmãs Franciscanas de Maristella sobre quais conteúdos poderiam interessar às comunidades. Dessa forma, ao mesmo tempo em que os facilitadores se apresentaram e trataram das noções iniciais sobre o que é Direito, buscaram conhecer melhor a realidade local e compreender quais seriam os principais problemas apontados pelos moradores, a fim de fortalecer o entendimento de quais deveriam ser os temas geradores (FREIRE, 2016). Procurou-se ouvir as narrativas para captar os signos e símbolos utilizados visando adequar a linguagem acadêmica e jurídica ao linguajar de Juruti Velho, fator de grande relevância para a Educação Popular adaptada ao contexto amazônico (HAGE; CORRÊA, 2019).

A questão do Território surgiu como uma das principais pautas das comunidades de Juruti Velho. Dentre as ameaças à soberania das populações tradicionais, destacaram-se a exploração ilegal de madeira e os impactos decorrentes da exploração minerária de bauxita pela multinacional Alcoa. Além disso, foi comentado a dificuldade em acionar as políticas públicas para a região devido à falta de interesse de governantes e a falta de conhecimento dos caminhos a serem seguidos pelas comunidades.

Diante dessas problemáticas, após as primeiras palavras trocadas e pronunciadas, em seguida ao encontro sobre Direitos e Garantias Fundamentais, o terceiro módulo do curso abordou o Direito ao Território e o Direito ao Meio Ambiente. Foram tratados de assuntos como Reforma Agrária, Relação de Beneficiários, Dominialidade, Posse Agrária, Plano de Manejo Florestal Sustentável, Plano de Uso, Ocupação da Amazônia, entre outros. Três momentos desse encontro se destacaram: o debate so-

\footnotetext{
${ }^{4}$ Partindo do Terminal Portuário de Santarém/PA são 12 horas de barco ou 5 horas de lancha até chegar em Juruti/PA. Ainda são mais duas horas de lancha ou 50 minutos de "voadeira" para chegar na Vila Muirapinima, em Juruti Velho.
} 
bre Certificado de Concessão de Direito Real de Uso (CCDRU); a oficina de elaboração de denúncias aos órgãos competentes; e a dinâmica para se pensar nas histórias das comunidades com os Territórios - pensar em memórias da infância.

A discussão sobre Direito ao Território foi promovida a partir da leitura coletiva da CCDRU do PAE Juruti Velho, momento em que muitas lideranças tiveram seu primeiro contato com o documento. O espaço de trocas de impressões foi importante para se perceber o caminho percorrido para se alcançar o acordo, mas também para compreendê-lo como algo que pode ser retirado das comunidades, caso elas deixem de permanecer articuladas.

$\mathrm{Na}$ oficina de elaboração de denúncias, os facilitadores fizeram uma apresentação dos principais órgãos públicos responsáveis por atuar em conflitos socioambientais nas esferas municipais, estaduais e federais, tais como: Instituto Nacional de Colonização e Reforma Agrária (INCRA), Instituto de Terras do Pará (ITERPA), Secretaria Municipal de Meio Ambiente (SEMMA), Ministério Público do Estado do Pará (MPPA), Ministério Público Federal (MPF), Defensoria Pública do Estado do Pará (DPPA), Defensoria Pública da União (DPU), Instituto Brasileiro do Meio Ambiente e dos Recursos Naturais Renováveis (IBAMA), Instituto Chico Mendes de Conservação da Biodiversidade (ICMBio). Em seguida, sortearam casos práticos de violações aos direitos socioambientais e solicitaram que os cursistas elaborassem em grupo os documentos com as informações necessárias e encaminhassem para o órgão adequado.

Noutro momento, a dinâmica sobre a relação com o Território mexeu bastante com o emocional dos participantes do curso, que compartilharam entre si bonitas histórias das suas famílias e a relação com a criação das comunidades. Nestas discussões, surgiram fortes inquietações sobre pertencimento e tradicionalidade, sobre como os moradores de Juruti Velho se consideram em relação a sua identidade. Como confirmar que realmente são comunidades tradicionais ${ }^{5}$ ? Essas reflexões não pode-

\footnotetext{
${ }^{5}$ A pesquisa de campo realizada por Monteiro (2009) atestou que as populações de Juruti Velho se reconhecem como populações tradicionais, não apenas pela ocupação secular da terra, mas também pela relação mantida com a natureza e a biodiversidade.
} 
riam ser trabalhadas superficialmente para se alcançar uma resposta satisfatória e então motivou a organização de um módulo específico para discutir sobre o Direito das Comunidades Tradicionais.

Neste módulo sobre Direito das Comunidades Tradicionais, debateu-se sobre os conceitos de tradicionalidade e identidade e os direitos consagrados no art. 231 da Constituição e na Convenção no 169 da Organização Internacional do Trabalho (OIT), dentre eles, Direito à Autodeterminação, Direito à Diferença, Direito ao Território (novamente), Direito à Cultura, Direito à Consulta Prévia, Livre e Informada. Este último contou com uma atenção especial para abordar a sua importância como instrumento de defesa do Território, a exemplo dos casos em que foi utilizado na região Oeste do Pará, como o dos Protocolos de Consulta dos Quilombolas do Maicá e dos Povos Indígenas Munduruku do Planalto, que foram utilizados para barrar a construção dos Portos do Maicá.

Num último encontro antes do encerramento do curso, durante o módulo sobre Direito à Cidade e Bem Viver, estava-se debatendo sobre as formas de resistência dos moradores locais aos impactos da mineração e foi lembrado sobre a ocupação da base de operações da Alcoa, ocorrida em 2009. Pelos relatos milhares de trabalhadores ocuparam a sede da empresa na Comunidade Capiranga, durante nove dias até conseguirem negociar as contraprestações para o funcionamento da exploração minerária. $\mathrm{Na}$ oportunidade, conseguiram que 1,5\% da lavra fossem destinadas diretamente à ACORJUVE.

Durante a empolgação, falou-se da vontade de registrar essas memórias para que as próximas gerações tenham conhecimento das lutas populares que o povo de Juruti Velho já protagonizou. Os membros do NAJUP Cabano se comprometeram com a ideia e, com apoio do Edital da Ufopa de incentivo a produções audiovisuais, das Irmãs Franciscanas de Maristella e dos participantes do Curso O Direito Achado na Beira do Rio, produziram o documentário 9 dias e nove noites. $\mathrm{O}$ projeto contou com o relato de diversas lideranças antigas das comunidades de Juruti Velho que protagonizaram a ocupação em 2009. Em fevereiro deste ano teve seu pré-lançamento na Vila Muirapinima e em julho foi exibido na III Mostra de Audiovisual da Ufopa. 
Desta maneira, podemos perceber que a Educação Jurídica Popular promovida pelo NAJUP Cabano junto com as lideranças comunitárias de Juruti Velho constitui-se em uma verdadeira ação cultural para a liberdade, como propõe Freire (2016, p. 97): “a ação política junto aos oprimidos tem de ser, no fundo, 'ação cultural' para a liberdade, por isto mesmo, ação com eles”. Entendendo que para a prática da liberdade dos moradores de Juruti Velho o Lago Muirapinima e todo o território abarcado no PAE Juruti Velho, a ação cultural (Educação Jurídica Popular Curso de Formação de Lideranças Comunitárias O Direito Achado na Beira do Rio) em defesa do território constitui-se em ação cultural para a liberdade.

A avaliação do curso revelou que os encontros na Vila Muirapinima fortaleceram o entendimento das lideranças comunitárias sobre alguns temas do direito e com isso auxiliaram no próprio processo de consolidação dos cursistas enquanto lideranças de suas comunidades. A maioria dos participantes são procurados pelas associações ou por moradores vizinhos para orientações de como resolver determinados conflitos, especialmente agroambientais e familiares.

Outro ponto destacado foi a habilidade dos facilitadores para a construção de um ambiente horizontal, onde todos se sentissem à vontade para contribuir com o debate. Essa era uma preocupação enorme do planejamento do curso - se não fosse a maior! - e foi uma grande felicidade poder receber a avaliação positiva nesse aspecto. Um dos principais objetivos do projeto era proporcionar um espaço onde as lideranças comunitárias rompessem o silenciamento em que são constantemente submetidas em espaços de poder e se reconhecessem enquanto sujeitos históricos donos de um saber próprio, um saber que não é menor ou maior que outros saberes. Almejou-se tornar possível um espaço onde os trabalhadores do campo pudessem ler o mundo e também ter esperança de dias melhores. Sonhar com outra sociedade (FREIRE, 2016).

Em contrapartida, foi cobrado dos facilitadores o desenvolvimento de mais atividades práticas, técnicas do direito, como a elaboração de contratos de compra e venda e outros documentos oficiais. Essa é uma crítica muito interessante para a compreensão do verdadeiro sentido político da Educação Jurídica Popular. Muitas vezes os educadores estão 
bastante preocupados com a dimensão "libertadora" da educação, no sentido mais amplo, de criar mecanismos para a promoção do diálogo horizontal, e acabam por deixar de lado o comprometimento com o ensino do conteúdo. Almeida (2015) denomina de "ilaraiê da Educação Popular" essa euforia dos estudantes em torno das técnicas pedagógicas da Educação Popular. Os facilitadores do curso O Direito Achado na Beira do Rio estavam alinhados com o oferecimento do ensino dos conteúdos sugeridos pela experiência das lideranças comunitárias de Juruti Velho, contudo, entende-se haver a necessidade melhorar nesse aspecto.

\section{Considerações finais}

Na Amazônia Paraense é notável a violenta invisibilização dos interesses de trabalhadores rurais, ribeirinhos e povos/comunidades tradicionais diante da força movida pelo grande capital, com o mercado diretamente interessado na dominação da região para exploração de seus recursos naturais. Apesar de todas as dificuldades encontradas pelo caminho, os filhos da terra continuam sua articulação política secular para a defesa de suas culturas, da floresta e das águas da região.

As comunidades de Juruti Velho, no oeste paraense, tiveram sua relação com a sociedade e com a natureza fortemente transformada pela chegada da multinacional Alcoa, com o objetivo de realizar a exploração de bauxita no Município de Juruti/PA. A empresa estadunidense exerce forte pressão sobre o território dos moradores históricos da região e, mesmo com uma proposta de Projeto Sustentável, gera ou reforça vários problemas (PORTELA, 2017).

Nesse sentido, a promoção do Curso de Formação de Lideranças Comunitárias O Direito Achado na Beira do Rio, organizado pelo NAJUP Cabano/UFOPA, em parceria com as Irmãs Franciscanas de Maristella, contribuiu com o fortalecimento das lideranças comunitárias para a atuação na proteção do território do PAE Juruti Velho. Os debates sobre Direitos e Garantias fundamentais foram importantes para a compreensão dos cursistas enquanto sujeitos de direitos; as discussões sobre o Direito à Terra e Direito ao Meio Ambiente auxiliaram no entendimento sobre a extensão dos direitos dos beneficiários do assentamento, bem 
como no esclarecimento do Projeto de Assentamento Agroextrativista enquanto modalidade de Reforma Agrária. O módulo sobre Direito dos Povos e Comunidades Tradicionais problematizou a questão da identidade dos moradores locais e debateu quais são os direitos desses grupos específicos diante do aparecimento de grandes projetos de "desenvolvimento". O tema do Direito à Cidade e Bem Viver instigou os cursistas a refletir sobre os seus horizontes de luta para a Cidade de Juruti/PA e para a Amazônia.

Assim, os diálogos ocorridos na Vila Muirapinima, apesar de conterem fragilidades metodológicas, serviram para a problematização da realidade das comunidades de Juruti Velho e também para o fortalecimento dos sujeitos locais na luta pela apropriação de seu território, no embate com a dominação exercida pelas forças exógenas - como a empresa Alcoa e, em alguns casos, o próprio Estado. Além disso, as trocas de conhecimentos à beira do Lago Muirapinima estimularam os cursistas a pensarem permanentemente sobre o seu lugar, a sua cultura e a sua identidade, a fim de se apossarem efetivamente do que é deles por direito.

Para respaldar este processo, a Educação Jurídica Popular, enquanto o conjunto de práticas educacionais propostas por professores, estudantes e profissionais das Ciências Jurídicas e Ciências Sociais, contribuiu para problematizar a realidade opressora das classes populares, mas especificamente o caso relatado neste texto, notadamente quanto aos conflitos que envolveram a necessidade de conhecimento de direitos e garantias fundamentais. A partir do diálogo sincero e amoroso entre os saberes científicos e os saberes populares, se almejou potencializar lutas pela efetivação de direitos desses sujeitos coletivos, ao mesmo tempo em que se buscou valorizar a humanidade historicamente retirada dos sujeitos marginalizados da sociedade juritiense.

\section{Referências}

AGUIAR, Lincon Sousa. O Direito Achado na Beira do Rio: o diálogo entre o NAJUP Cabano e as lideranças comunitárias de Juruti Velho. Monografia. 
Curso de Ciências Jurídicas. Universidade Federal do Oeste do Pará. Santarém/PA, 2020.

ALMEIDA, Ana Lia Vanderlei de. Um estalo nas faculdades de direito: perspectivas ideológicas da Assessoria Jurídica Universitária Popular. Tese (Doutorado em Direito) - Universidade Federal da Paraíba. João Pessoa, 2015.

BEZERRA, Hélio Miguel Santos; BICHARA, Jahyr-Philippe. Os aspectos conceituais da Educação Jurídica Popular. Interface - Natal/RN - v.7 - n. 1 jan./jun. p. 83-92, 2010.

BRANDÃO, Carlos Rodrigues. O que é educação popular. São Paulo: Editora Brasiliense, 1981.

BRASIL. Constituição (1988). Constituição da República Federativa do Brasil. Brasília, DF: Senado Federal: Centro Gráfico, 1988.

CORRÊA, Ludmila Cerqueira. Por uma Pedagogia da Loucura: experiências de assessoria jurídica popular universitária no contexto da Reforma Psiquiátrica brasileira. Tese (Doutorado em Direito) - Universidade de Brasília. Brasília, 2018.

CRUZ, Valter do Carmo. O rio como espaço de referência identitária: reflexões sobre a identidade ribeirinha na Amazônia. In: TRINDADE JUNIOR, SaintClair Cordeiro da; TAVARES, Maria Goretti da Costa. Cidades ribeirinhas na Amazônia: mudanças e permanências. Belém: EDUFPA, 2008.

FREIRE, Paulo. Educação como prática da liberdade. ed. 38. São Paulo, Paz e Terra, 2014.

2013.

. Extensão ou comunicação?. Ed. 16ª Rio de Janeiro: Paz e Terra, . Pedagogia do Compromisso: América Latina e Educação Popular. Rio de Janeiro/São Paulo: Paz e Terra, 2018.

. Pedagogia do Oprimido. 60. ed. Rio de Janeiro: Paz e Terra, 2016.

FRIGOTTO, Gaudêncio. Fundamentos científicos e técnicos da relação trabalho e educação no Brasil de hoje. In: LIMA, Júlio Cesar França; NEVES, Lúcia Wanderley. (orgs.). Fundamentos da educação escolar do Brasil contemporâneo. Rio de Janeiro: Fiocruz, 2006. p. 241-288.

HAESBERT, Rogério. Território e Multiterritorialidade: um debate. Revista GEOgraphia - Ano IX, n. 17, p. 19-46, 2007. 
HAGE, Salomão A. M.; CORRÊA, Sérgio Roberto Moraes. Educação Popular e Educação do Campo na Amazônia: análise a partir dos Movimentos Sociais. RTPS - Rev. Trabalho, Política e Sociedade, Vol. IV, nº 07, p. 123-142, jul.dez./2019

\section{LOPES, Luis Otávio do Canto. Conflito socioambiental e (re)organização}

territorial: mineradora Alcoa e comunidades ribeirinhas do Projeto de Assentamento Agroextrativista Juruti Velho, município de Juruti-Pará-Amazônia-Brasil . Tese (Doutorado) - Universidade Federal do Rio Grande do Sul, Faculdade de Ciências Econômicas, Programa de Pós-Graduação em Desenvolvimento Rural, Porto Alegre, 2012.

LUZ, Vladimir de Carvalho. Assessoria jurídica popular no Brasil : paradigmas, formação histórica e perspectivas. Rio de Janeiro: Editora Lumen Juris, 2008.

MARIALVA, Dilza Azevedo. Novas dinâmicas territoriais na Amazônia: desdobramentos da mineração da bauxita em Juruti (PA) . Dissertação (Mestrado) - Universidade de São Paulo, Faculdade de Filosofia, Letras e CiÊncias Humanas, Programa de Pós-Graduação em Geografia Humana, São Paulo. São Paulo/SP, 2011.

MÉSZÁROS, István. A educação para além do capital. ed. 2. São Paulo: Boitempo, 2008.

MONTEIRO, Mara Rúbia Muniz. A Democratização da sociedade: participação das organizações da sociedade civil-experiências em Juruti Velho-PA. Dissertação (Mestrado) - Universidade Federal do Pará, Núcleo de Altos Estudos Amazônicos, Programa de Pós-Graduação em Planejamento do Desenvolvimento, Belém, 2009.

MONTOIA, Gustavo Rodrigo Milaré; COSTA, Sandra Maria Fonseca da. O ribeirurbano e as cidades da Amazônia: a construção de uma antropogeografia.

Novos Cadernos NAEA. v. 22, n. 2, p. 183-204, maio-ago 2019.

PORTELA, Everaldo Machado. Mineração em Juruti: do desenvolvimento ao desenvolvimento sustentável? Tese (Doutorado) - Universidade Federal do Oeste do Pará. Santarém, 2017.

ROTONDANO, Ricardo Oliveira. Movimentos sociais e educação jurídica popular: estratégias de atuação coletiva para a consecução de direitos. Dissertação (Mestrado em Direito) - Universidade de Brasília, Programa de Pós-Graduação em Direito. Brasília. 2015. 
OLIVEIRA, Ivanilde Apoluceno de. Diretrizes metodológicas freireanas e a educação jurídica popular. Revista InSURgência. Brasília. Ano 1, v. 1, n.1, jan./jun, p. 16-31, 2015.

SANTOS, Boaventura de Sousa. A Universidade no século XXI: para uma reforma democrática e emancipatória da Universidade. ed. 3. São Paulo: Cortez, 2011.

SEVERINO, Antônio Joaquim. Fundamentos ético-políticos da educação no Brasil de hoje. In: LIMA, Júlio Cesar França; NEVES, Lúcia Wanderley. (orgs.). Fundamentos da educação escolar do Brasil contemporâneo. Rio de Janeiro: Fiocruz, 2006. p. 289-320

SILVA, Ivana de Oliveira; SILVA, Paulo Lucas da. Usos do conceito geográfico "território" e sua relevância na análise de conflitos territoriais e socioambientais na Amazônia. Revista Pegada - Vol. 17, n. 1, p. 47-66, jun,/2016.

SILVA, Lindomar de Jesus Sousa. Natureza capitalista versus natureza orgânica: o advento da ALCOA e a mobilização e organização das comunidades de Juruti no Baixo Amazonas. Tese (Doutorado) - Universidade Federal do Pará, Núcleo de Altos Estudos Amazônicos, Programa de Pós-Graduação em Desenvolvimento Sustentável do Trópico Úmido, Belém, 2014.

SOUSA JÚNIOR, José Geraldo de. Direito como Liberdade: o direito achado na rua experiências populares emancipatórias de criação do direito. Porto Alegre: Sergio Antonio Fabris Editor, 2011.

- (Org.). Introdução crítica do direito: série o direito achado na rua. $4^{\mathrm{a}}$ ed. Brasília: Editora da UnB, 1993.

SOUZA, Sirley Aparecida de. Educação Jurídica Popular: Identidade e protagonismo de novos sujeitos de Direito. Tese (Doutorado) - Universidade Federal de Goiás (UFG). Programa de Pós-Graduação Stricto Senso em Educação, 2019.

STRECK, Lenio Luiz; MORAIS, Jose Luis Bolzan de. Ciência Política e Teoria do Estado. ed. 8. Porto Alegre: Livraria do Advogado Editora, 2014.

WANDERLEY, Luiz Jardim de Moraes. Conflitos e Movimentos Sociais Populares em Área de Mineração na Amazônia Brasileira. Dissertação de Mestrado - Universidade Federal do Rio de Janeiro, Programa de Pós-Graduação em Geografia, curso de mestrado em Geografia, 2008. 
WOLKMER, Antônio Carlos. Introdução ao pensamento jurídico crítico. $4^{a}$ ed. São Paulo: Saraiva, 2002. 